\title{
Emerging knock-down resistance in Anopheles arabiensis populations of Dakar, Senegal: first evidence of a high prevalence of kdr-e mutation in West African urban area
}

\author{
Mamadou Ousmane Ndiath ${ }^{1,2^{*}}$, Aurélie Cailleau ${ }^{3}$, Eve Orlandi-Pradines ${ }^{4}$, Paul Bessell $^{5}$, Fréderic Pagès ${ }^{4}$, \\ Jean-François Trape ${ }^{2}$ and Christophe Rogier ${ }^{4,6}$
}

\begin{abstract}
Background: Urban malaria is now considered a major emerging health problem in Africa and urban insecticide resistance may represent a serious threat to the ambitious programme of further scaling-up coverage with longlasting insecticide-treated bed nets and indoor residual spray. This study evaluates the levels and mechanisms of insecticide resistance in Anopheles gambiae populations in 44 urban areas of Dakar in a longitudinal entomological surveillance study.
\end{abstract}

Methods: Adult mosquitoes sampled by night-landing catches at 44 sites across Dakar from 2007 to 2010 were genotyped to assess the frequency and distribution of resistance alleles. In addition World Health Organization susceptibility tests to six insecticides were performed on F0 adults issuing from immature stages of An. gambiae s.l. sampled in August 2010, 2011 and 2012 in three sites of Dakar: Pikine, Thiaroye and Almadies and repeated in 2012 with three of the insecticides after PBO exposure to test for mechanisms of oxydase resistance. Species, molecular forms and the presence of $k d r$ and ace- 1 mutations were assessed by polymerase chain reaction.

Results: High frequencies of the kdr-e allele, ranging from 35 to $100 \%$, were found in Anopheles arabiensis at all 44 sites. The insecticide susceptibility tests indicated sensitivity to bendiocarb in Almadies in 2010 and 2011 and in Yarakh between 2010 and 2012 and sensitivity to fenitrothion in Almadies in 2010. The mortality rate of EE genotype mosquitoes was lower and that of SS mosquitoes was higher than that of SE mosquitoes, while the mortality rate of the SW genotype was slightly higher than that of the SE genotype. Pyperonyl butoxide (PBO) had a significant effect on mortality in Pikine $(\mathrm{OR}=1.4,95 \% \mathrm{Cl}=1.3-1.5$, with mortality of 42-55\% after exposure and $11-17 \%$ without $\mathrm{PBO})$ and Yarakh $(\mathrm{OR}=1.6,95 \% \mathrm{Cl}=1.4-1.7$, with mortality of 68-81 \% after exposure and 23-37 \% without), but not in Almadies (OR $=1.0,95 \% \mathrm{Cl}=0.9-1.1)$.

Conclusion: A high prevalence of kdr-e in West Africa was demonstrated, and knock-down resistance mechanisms predominate although some oxidases mechanisms (cytochrome P450 monooxygenases) also occur. In view of the increased use of insecticides and the proposed role of the $k d r$ gene in the susceptibility of Anopheles to Plasmodium, this finding will significantly affect the success of vector control programmes.

Keywords: Anopheles, Urban malaria, Insecticide resistance, kdr-e, Dakar, Senegal

\footnotetext{
*Correspondence: ousmane.ndiath@gmail.com

${ }^{1}$ Groupe G4 Institut Pasteur International Network, Institut Pasteur de

Bangui, BP 237, Bangui, Central African Republic

Full list of author information is available at the end of the article
} 


\section{Background}

Resistance of malaria vectors to insecticides is a major concern for public health authorities and especially for national malaria control programmes in Africa, where the prevention of this devastating disease relies heavily on the use of pesticides to control the vector mosquito populations [1-3]. Currently, pyrethroids are the only class of insecticide approved for treating bed nets, and they are used preferentially to treat long-lasting insecticide-treated bed nets because of their effectiveness, with a strong excito-repellent effect on mosquitoes, and lower mammalian toxicity than organochlorine, carbamate and organophosphate compounds [4].

Various mechanisms enable Anopheles to resist the action of insecticides, including metabolic resistance, target-site resistance, reduced penetration and behavioural resistance. These mechanisms may allow mosquitoes to resist more than one insecticide (cross-resistance), and Anopheles may express more than one resistance mechanism (multiple resistances). Of all types of resistance, perhaps the most significant in Anopheles gambiae populations is knockdown resistance $(k d r)$ [5]. Two point mutations at amino acid position 1014 of the voltagegated sodium channel gene result in either a leucinephenylalanine (L1014F, $k d r-w)$ [6] or a leucine-serine (L1014S, $k d r-e$ ) mutation [7] in An. gambiae populations mainly in West and East Africa, respectively. A number of studies, with limited geographical sampling, have shown the distribution of $k d r$ mutations in An. gambiae, with screening for the L1014F allele in West Africa [810] and the L1014S mutation in East Africa [7].

Increases in the prevalence of these mutations have been reported, which may be due to intensive use of DDT and pyrethroids for crop protection, particularly cotton, and for public health purposes. Use of pyrethroids in agriculture and for treating nets has been recognized as a factor in the selection of resistant mosquitoes in subSaharan Africa [11, 12]. The presence of the two resistance alleles has been studied in Nigeria [13], Benin [14], Cameroon [15], Equatorial Guinea [16], Gabon [17], Uganda [18], Kenya and the United Republic of Tanzania [19], Malawi and Mozambique [20], but so far not in Senegal, the far west of the continent [21].

Malaria is a major public health concern in Senegal. It occurs throughout the year, with a peak during the rainy season. Since 2000, the national malaria control programme has elaborated 5-year action plans, which were successfully implemented with partners [22]. The aim of the latest plan (2006-2010) was to reduce mortality and morbidity from malaria by $50 \%$. Between the beginning of 2006 and the end of 2009, proportional morbidity due to malaria fell from 33.6 to $3.1 \%$ and proportional mortality from 18.2 to $4.4 \%$ $[2,22]$. These results were due to wide-scale treatment of malaria with artemisinin-based combination therapy, generalized use of free rapid diagnostic tests to confirm malaria, massive distribution of long-lasting insecticide-treated bed nets for the most vulnerable people and indoor residual spraying with pyrethroids $[23,24]$.

Urbanization used to be thought to reduce malaria transmission [25], but this view is changing, and urban malaria is now considered a major emerging health problem in Africa [26]. The rapid, unplanned growth of towns and cities generally results in inferior housing, poor sanitation and increased pollution, all of which could affect the distribution and abundance of mosquito vectors [27, 28]. Invasion of these 'urban islands' by malaria vectors, mainly Anopheles arabiensis, can be attributed to local adaptation and use of atypical breeding sites, such as polluted water pools or ditches [29, 30]. Urban insecticide resistance might therefore represent a serious threat to the ambitious programme of further scaling-up coverage with long-lasting insecticide-treated bed nets.

No study has been conducted to assess whether urbanization is a threat to malaria control in Senegal. To test this hypothesis, a longitudinal entomological surveillance study was initiated, with monitoring of the level and mechanisms of insecticide resistance in An. arabiensis populations at three urban sites near Dakar.

\section{Methods}

\section{Study area}

This study is part of the Urban Malaria Project, which has been described in detail elsewhere [21]. Briefly, Dakar $\left(14^{\circ} 40^{\prime} 20^{\prime \prime}\right.$ North, $17^{\circ} 25^{\prime} 22^{\prime \prime}$ West), the capital city of Senegal, is located on the Cap-Vert peninsula at the western-most point of Africa. The population was estimated at $1,030,594$ in 2005 , representing about $20 \%$ of the country's population, with a population density of 12,233 per $\mathrm{km}^{2}$. The altitude does not exceed $104 \mathrm{~m}$. The study reported here was conducted in 44 different areas of downtown Dakar and in Pikine, Thiaroye and Guediawaye, three of Dakar's satellite cities. The urbanization, climate and characteristics of these areas have been described in detail $[21,30,31]$.

\section{Mosquito collection}

Adult mosquitoes were collected in the 45 areas of Dakar city by human landing catches once every 2 weeks in September-October 2007, during the extended wet season (July-December) in 2008 and 2009 and once every month during the dry season (January-June) in 2009 and 2010 by indoor and outdoor collections. These mosquitoes were identified and genotyped to assess the frequency and distribution of resistant alleles across the study area.

Immature stages of An. gambiae s.l. were collected from 10 breeding sites in three of 44 areas: Almadies, Yarakh and 
Pikine in August 2010, 2011 and 2012, during the rainy season. Larvae from each area were pooled, fed Tetramin ${ }^{\circledR}$ baby fish food and allowed to emerge locally. These mosquitoes were used for susceptibility tests, and a subset was further identified and genotyped to assess the mechanisms of resistance.

\section{Susceptibility testing}

Unfed 2 to 3-day-old female An. gambiae s.l. mosquitoes grown from larvae collected in 2010, 2011 and 2012 were used for insecticide susceptibility tests. Bioassays were carried out with World Health Organization (WHO) test kits for adult mosquitoes [32] on six insecticides of technical-grade quality: one carbamate $(0.1 \%$ bendiocarb), one organophosphate ( $1 \%$ fenitrothion), three pyrethroids $(0.05 \% \lambda$-cyhalothrin, $0.05 \%$ deltamethrin, $0.75 \%$ permethrin) and one organochlorine (4\% DDT). Papers impregnated with these insecticides were obtained from the WHO reference centre (Vector Control Research Unit, University Sains Malaysia, Penang, Malaysia).

Tests were performed with four batches of 25 mosquitoes exposed to each insecticide for $1 \mathrm{~h}$ at $25-27^{\circ} \mathrm{C}$ and $80 \%$ relative humidity, and the number of mosquitoes knocked down was recorded after 10, 15, 20, 30, 40, 50 and $60 \mathrm{~min}$. After exposure, the mosquitoes were kept in observation tubes and supplied with a $10 \%$ sugar solution. Mortality was recorded after $24 \mathrm{~h}$. A control strain (An. gambiae M form, from Yaoundé, named 'Boudin' [24]), which is known to be $100 \%$ susceptible to DDT, was used as a positive control, and batches exposed to untreated paper were used as negative controls. As the mortality rate in negative controls was always $<5 \%$, no adjustment was performed for treated batches. Resistant and susceptible mosquitoes were preserved separately in Eppendorf tubes filled with desiccated silica gel.

\section{Synergism bioassays}

Unfed 2 to 3-day-old female An. gambiae s.l. grown from larvae collected in 2012 were used for synergism bioassays. The mosquitoes were exposed to $4 \%$ pyperonyl butoxide (PBO) for $1 \mathrm{~h}$ to suppress oxidase resistance mechanisms (cytochrome P450 monooxygenases), leaving only other mechanisms of resistance to be measured. Two batches of 25 mosquitoes were then immediately exposed to $0.05 \%$ deltamethrin, $0.75 \%$ permethrin or $4 \% \mathrm{DDT}$ for another $1 \mathrm{~h}$; controls were exposed to $\mathrm{PBO}$ only. Knockdown (KDT) was recorded every $10 \mathrm{~min}$ during the 1-h exposure. The mosquitoes were then transferred into holding tubes and supplied with a $10 \%$ sugar solution. Final mortality was recorded after $24 \mathrm{~h}$. Resistant and susceptible mosquitoes were preserved separately in Eppendorf tubes filled with desiccated silica gel.

\section{DNA extraction, molecular identification and detection of mutations}

$K d r-w$ (L1014F) and $k d r-e$ (L1014S) mutations and insensitive G119S (ace-1) point mutations were detected by polymerase chain reaction, as described previously [33, 34], in adult mosquitoes sampled by human landing catch during the longitudinal study and in a subset of the subsample of mosquitoes used for susceptibility testing. This subset was made as fellow: for each insecticide, site and year, 25 mosquitoes were genotyped, of which approximately half were alive and half dead after their exposure within the susceptibility testing. A restriction fragmentlength polymorphism assay was also performed to identify members of the An. gambiae complex and M and S molecular forms simultaneously [35].

\section{Data analysis}

Four datasets were analysed: (1) the identification and genotypes of the collected adult mosquitoes; (2) the results of susceptibility testing; (2b) the results for the subsample of these mosquitoes that were also genotyped; and (3) the results of the synergism bioassay.

Dataset 1 was used to determine the spatial distribution of the $k d r$ mutation.

Dataset 2 to assess levels of resistance and their variations and dataset $2 \mathrm{~b}$ and 3 their mechanisms.

In order to assess the level of resistance at each site and for each year according to WHO standards, mortality rates was calculated after $24 \mathrm{~h}$ and their confidence intervals (CIs). If the mortality rate was $<80 \%$, the mosquitoes were considered resistant; if the rate was $80-98 \%$, the mosquitoes were considered increasingly tolerant; and if the rate was $>98 \%$, the mosquitoes were considered to be sensitive. In addition, a probit log-time model of which only significant terms had been retained was adjusted on the first hour mortalities (kinetics) to determine 50 and $95 \%$ knockdown times $\left(\mathrm{KDT}_{50}\right.$ and $\left.\mathrm{KDT}_{95}\right)$ for each site and each year as well.

In order to assess whether the levels of resistance varied significantly over time and space, a generalized linear model with binomial error structure (logistic regression) was used, with year, site and insecticide as the explanatory variables and $24 \mathrm{~h}$ mortality as the response variable. The design was balanced, with 100 mosquitoes per year, site and insecticide $(N=5399)$.

Mechanisms of resistance were assessed from dataset $2 \mathrm{~b}$, from the relations between genotypes at the $k d r$ and ace 1 loci and mortality, and from dataset 3 , which indicated the extent of oxidase resistance.

The sampling method for dataset $2 \mathrm{~b}$ corresponded to a case-control design, and it was therefore analysed accordingly. Logistic regression was performed with mortality as a response variable, genotype as an explanatory variable and year, site, insecticide and insecticide-site interaction 
as control variables, as they were shown to affect mortality significantly in analyses of variation in levels of resistance over time and space. A rare event correction [36] was performed (with weights calculated using dataset 2) to allow for interpretable estimates of mortality for the different genotypes despite the case control sampling design. The logistf R library was used to compute the: confidence intervals of these mortalities from the profile-penalized log likelihood. The SE genotype was selected as the baseline for pairwise comparisons because it shares one allele with all the other genotypes (SS, SW and EE). The significance of variables was tested with the drop1 $\mathrm{R}$ function.

A logistic model was used on a combined subset of dataset 2 (bioassays) and dataset 3 (synergism assays) after DDT, permethrin and deltamethrin treatment in 2012. The response variable was mortality; the explanatory variables were insecticide, site and exposure to PBO before the insecticide (Yes/ No). Type II sum of squares was used to test significance.

\section{Results}

\section{Spatial distribution of $k d r$ mutation}

A total of 44,967 mosquitoes were captured between 2007 and 2010 across the 44 sites of Dakar and its three satellite cities. 3753 An. gambiae s.l. were identified at species level. Anopheles arabiensis represented $93.15 \%$ $(\mathrm{n}=3496)$ of the anophelines and Anopheles melas represented $6.84 \%(\mathrm{n}=257)$.

The $k d r-e$ allele was observed in $35-100 \%$ of these mosquitoes at all sites, showing no clear overall spatial pattern (Fig. 1). Of the 44 sites, 41 had a frequency of at least $75 \%$ of the EE genotype; the SE genotype reached a level of about $15 \%$, particularly in west, in the region of the airport (Additional file 1). In 2007, there is a higher prevalence of ES genotype in the west compared to 2008 and 2009, when the prevalence of EE genotypes was equally high throughout the region (Additional file 1).

\section{Insecticide resistance}

Sensitivity to bendiocarb was observed in Almadies in 2010 and 2011 and in Yarakh between 2010 and 2012, and to fenitrothion in Almadies in 2010. Increased tolerance was observed to bendiocarb in Almadies in 2013 and in Pikine in 2010, and to fenitrothion in Almadies in 2011 and 2012 and in Yarakh in 2010. Resistance was observed otherwise (i.e. to all other insecticides, year, site) (Fig. 2; Additional file 2). The values of $\mathrm{KDT}_{50}$ and

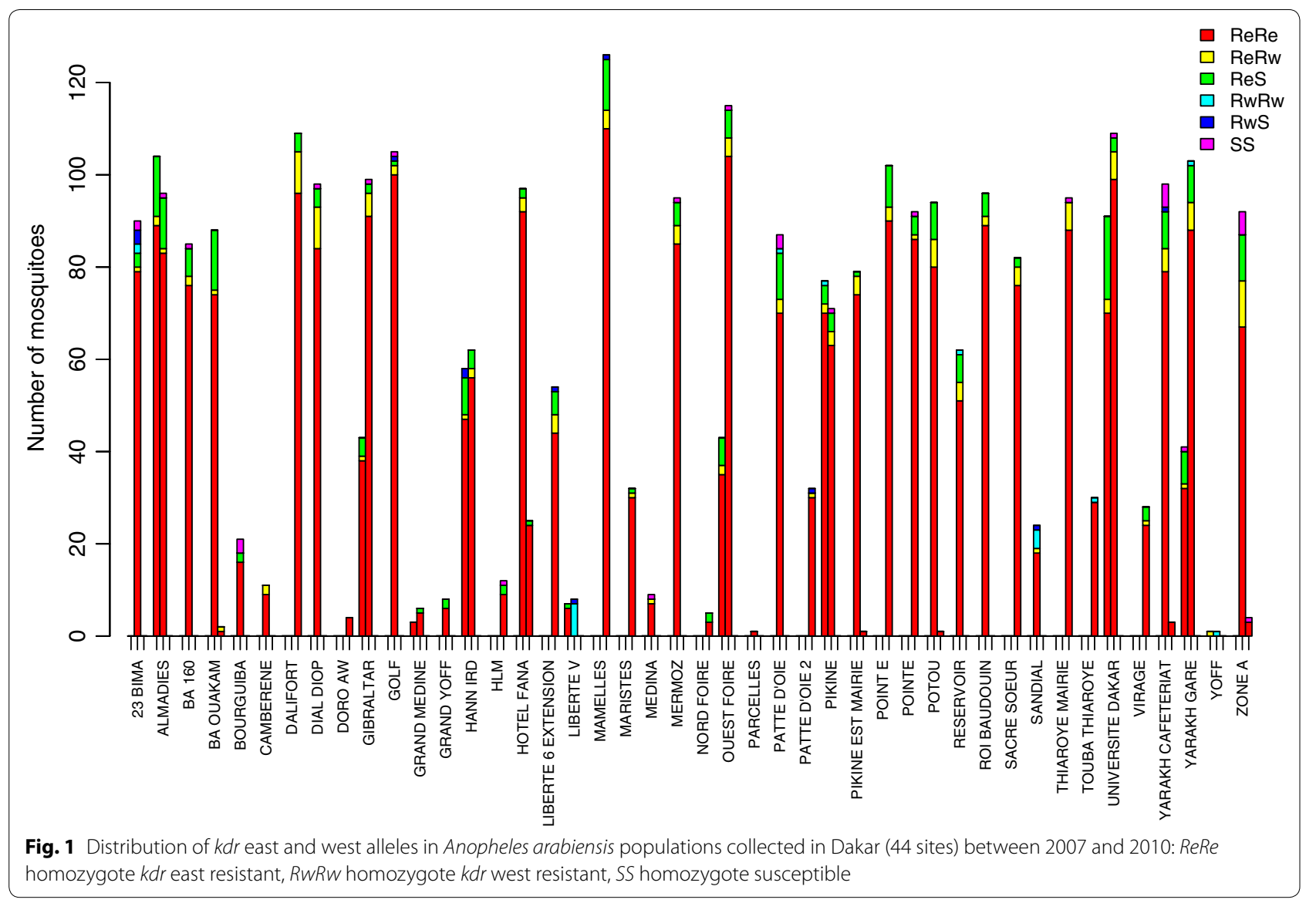



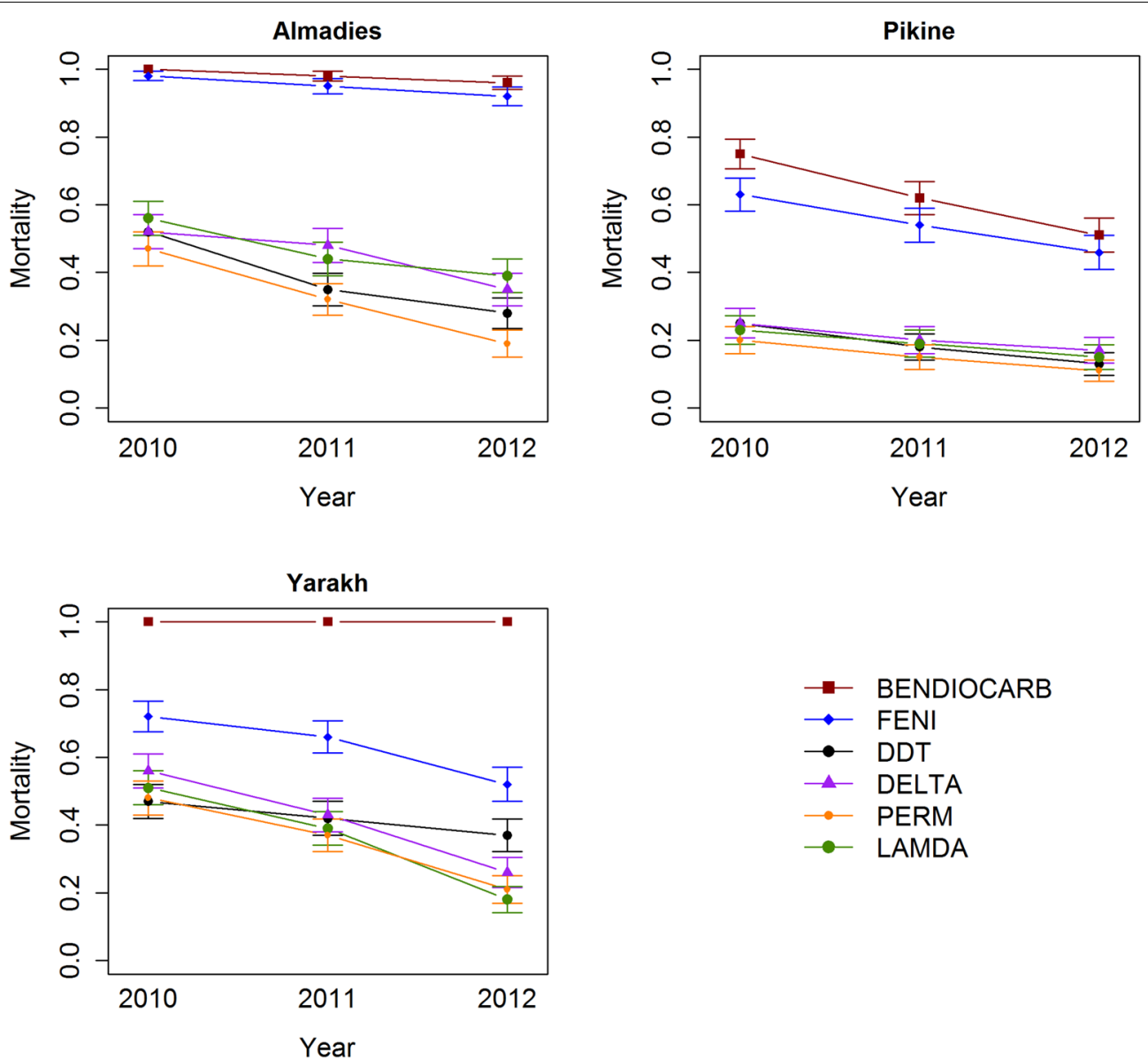

ages. Error bars represent $95 \% \mathrm{Cl}$

$\mathrm{KDT}_{95}$ are given for each site and each year in Table 1. These could not be determined for most insecticides at most sites, as mortalities 50 and $95 \%$ were not reached. Insecticide, year and site all had a significant effect on mortality $(p<2.2 \mathrm{e}-16)$, as did the site-insecticide interaction. The year-insecticide and site-year interactions were not significant (Table 2; Fig. 2; Additional file 2).

\section{Mechanisms of resistance}

All the mosquitoes genotyped and identified are $A n$. arabiensis. None of them had the ace-1 resistant allele, but $k d r$ resistant alleles were found. In the analysis of the relation between insecticide-induced mortality and genotype at the $k d r$ locus (dataset $2 \mathrm{~b}$ ), all the explanatory variables, including genotype, were significant $\left(\chi^{2}=68.86\right.$, $\mathrm{df}=3$, $\mathrm{p}=7.44 \mathrm{e}-15)$. As expected, the mortality rate of EE genotype mosquitoes was lower than that of SE mosquitoes $(\mathrm{OR}=0.225,95 \% \mathrm{CI}=0.213-0.239)$, while the mortality rate of SS mosquitoes was higher $(\mathrm{OR}=1418,95 \%$
$\mathrm{CI}=89-22,708)$. Note the latter OR is highly inaccurate because the mortality rate was close to 1 . The mortality rate of the SW genotype was slightly higher than that of the SE genotype (OR $=3.192,95 \% \mathrm{CI}=2.631-3.872)$. A trend to decreasing mortality was seen between 2010 and 2012 in each locality and for each $k d r$ genotype (Additional file 3).

The model used to analyse dataset 3 showed an effect of insecticide and site and their interaction, consistent with our previous results. Moreover, $\mathrm{PBO}$ and the interaction between site and PBO exposure had significant effects. Interestingly, the interaction between exposure to $\mathrm{PBO}$ and insecticide was not significant (Table 3). As the effect of $\mathrm{PBO}$ varied by site, a subset logistic regression was conducted to assess the effect of PBO for each site separately (Table 4). PBO exposure significantly increased mortality among mosquitoes from Pikine $(\mathrm{OR}=1.4,95 \% \mathrm{CI}=1.3-1.5)$ and Yarakh $(\mathrm{OR}=1.6$, $95 \% \mathrm{CI}=1.4-1.7)$ but not in Almadies (OR $=1.0,95 \%$ $\mathrm{CI}=0.9-1.1)$. 
Table 1 Bioassay susceptibility tests on Anopheles arabiensis populations from Almadies, Pikine and Yarakh: evolution of the $K D_{50}$ and $K D_{95}$ by year and by insecticides

\begin{tabular}{|c|c|c|c|c|c|c|c|c|c|c|c|c|c|}
\hline \multirow[t]{2}{*}{ Site } & \multirow[t]{2}{*}{ Year } & \multicolumn{2}{|c|}{ Bendiocarb } & \multicolumn{2}{|l|}{ DDT } & \multicolumn{2}{|c|}{ Deltamethrin } & \multicolumn{2}{|c|}{ Fenitrothion } & \multicolumn{2}{|c|}{$\lambda$-Cyhalothrin } & \multicolumn{2}{|c|}{ Permethrin } \\
\hline & & $\mathrm{KDT}_{50}$ & $\mathrm{KDT}_{95}$ & $\mathrm{KDT}_{50}$ & $\mathrm{KDT}_{95}$ & $\mathrm{KDT}_{50}$ & $\mathrm{KDT}_{95}$ & $\mathrm{KDT}_{50}$ & $\mathrm{KDT}_{95}$ & $\mathrm{KDT}_{50}$ & $\mathrm{KDT}_{95}$ & $\mathrm{KDT}_{50}$ & $\mathrm{KDT}_{95}$ \\
\hline \multirow[t]{3}{*}{ Almadies } & 2010 & 14 & 50 & - & - & 5 & - & 47 & - & 37 & - & - & - \\
\hline & 2011 & 14 & 60 & - & - & - & - & 46 & - & - & - & - & - \\
\hline & 2012 & 16 & - & - & - & - & - & 53 & - & - & - & - & - \\
\hline \multirow[t]{3}{*}{ Pikine } & 2010 & - & - & - & - & - & - & - & - & - & - & - & - \\
\hline & 2011 & - & - & - & - & - & - & - & - & - & - & - & - \\
\hline & 2012 & - & - & - & - & - & - & - & - & - & - & - & - \\
\hline \multirow[t]{3}{*}{ Yarakh } & 2010 & 15 & 35 & - & - & 57 & - & - & - & - & - & - & - \\
\hline & 2011 & 16 & 38 & & - & - & - & & - & - & - & - & - \\
\hline & 2012 & 21 & 55 & - & - & - & - & - & - & - & - & - & - \\
\hline
\end{tabular}

-: As no mosquitoes were knocked down, we were unable to measure $\mathrm{KDT}_{50}$ and $\mathrm{KDT}_{95}$

Table 2 Bioassay susceptibility tests in Anopheles arabiensis populations from Almadies, Pikine and Yarakh: significance and effect of site, year and insecticide on insecticide-induced mortality

\begin{tabular}{|c|c|c|c|c|c|}
\hline & Df & Deviance & Residual Df & Residual Dev & $\operatorname{Pr}\left(>\chi^{2}\right)$ \\
\hline Null & & & 5398 & 7476.2 & \\
\hline Site & 2 & 305.20 & 5396 & 7171.0 & $<2 \mathrm{e}-16$ \\
\hline Year & 1 & 102.96 & 5395 & 7068.0 & $<2 \mathrm{e}-16$ \\
\hline Insecticide & 5 & 1277.32 & 5390 & 5790.7 & $<2 \mathrm{e}-16$ \\
\hline $\begin{array}{l}\text { Site-insecti- } \\
\text { cide }\end{array}$ & 10 & 199.02 & 5378 & 5590.1 & $<2 \mathrm{e}-16$ \\
\hline Site-year & 2 & 1.59 & 5388 & 5789.1 & 0.4507 \\
\hline $\begin{array}{l}\text { Year-insecti- } \\
\text { cide }\end{array}$ & 5 & 4.61 & 5373 & 5585.5 & 0.4659 \\
\hline $\begin{array}{l}\text { Site-year- } \\
\text { insecticide }\end{array}$ & 10 & 10.48 & 5363 & 5575.0 & 0.3994 \\
\hline
\end{tabular}

Table 3 Effect of PBO exposure on the susceptibility of Anopheles arabiensis populations from Almadies, Pikine and Yarakh: interaction between site, PBO and insecticide

\begin{tabular}{lrlll}
\hline & LR $\boldsymbol{\chi}^{\mathbf{2}}$ & Df & $\operatorname{Pr}\left(>\boldsymbol{\chi}^{\mathbf{2}}\right)$ & Significance \\
\hline Insecticide & 12.344 & 2 & 0.002087 & $* *$ \\
Site & 40.166 & 2 & $1.897 \mathrm{e}-09$ & $* * *$ \\
PBO & 102.936 & 1 & $<2 e-16$ & $* * *$ \\
Insecticide-site & 11.603 & 4 & 0.020563 & $*$ \\
Insecticide-PBO & 0.665 & 2 & 0.717253 & \\
Site-PBO & 43.937 & 2 & $2.879 \mathrm{e}-10$ & $* * *$ \\
Insecticide-site-PBO & 1.940 & 4 & 0.746827 & \\
\hline
\end{tabular}

*** $p$ value $<0.001 ;{ }^{* *} \mathrm{p}$ value $(0.001-0.01) ;{ }^{*} \mathrm{p}$ value $(0.01-0.05)$

For Pikine, mosquito mortality ranged from 42 and $55 \%$, depending on the insecticide, after PBO exposure but from 11 to $17 \%$ without PBO exposure. For Yarakh, mosquito mortality ranged from 68 to $81 \%$ after $\mathrm{PBO}$
Table 4 Effect of PBO exposure on susceptibility of Anopheles arabiensis populations from Almadies, Pikine and Yarakh

\begin{tabular}{|c|c|c|c|c|}
\hline & $\operatorname{LR} \chi^{2}$ & Df & $\operatorname{Pr}\left(>x^{2}\right)$ & Significance \\
\hline \multicolumn{5}{|l|}{ Almadies } \\
\hline Insecticide & 11.5119 & 2 & 0.003164 & $* *$ \\
\hline PBO exposure & 0.0901 & 1 & 0.764034 & \\
\hline \multicolumn{5}{|l|}{ Pikine } \\
\hline Insecticide & 2.957 & 2 & 0.2279 & \\
\hline PBO exposure & 75.473 & 1 & $<2 \mathrm{e}-16$ & $* * *$ \\
\hline \multicolumn{5}{|l|}{ Yarakh } \\
\hline Insecticide & 9.44 & 2 & 0.008915 & $* *$ \\
\hline PBO exposure & 100.66 & 1 & $<2.2 \mathrm{e}-16$ & $* * *$ \\
\hline
\end{tabular}

exposure but from 23 to $37 \%$ without exposure. For Almadies, mosquito mortality was $18-35 \%$, independently of PBO exposure (Fig. 3; Additional files 2, 4).

\section{Discussion}

Mosquitoes were resistant to most of the insecticides at most sites. Resistance to bendiocarb appeared to have progressed less than that to other insecticides, as no resistance to this insecticide was found in 2010. Mosquitoes in Yarakh remained sensitive until 2012, but those in Pikine were significantly resistant and those in Almadies showed increased tolerance to this insecticide up to 2011. The KDT values in response to fenitrothion and bendiocarb were similar in 2010 and 2011 but increased markedly between 2011 and 2012, indicating accelerated change. The impossibility to determine $\mathrm{KDT}_{50}$ and $\mathrm{KDT}_{95}$ for most molecules indicates high levels of resistances, in particular knockdown resistance. 

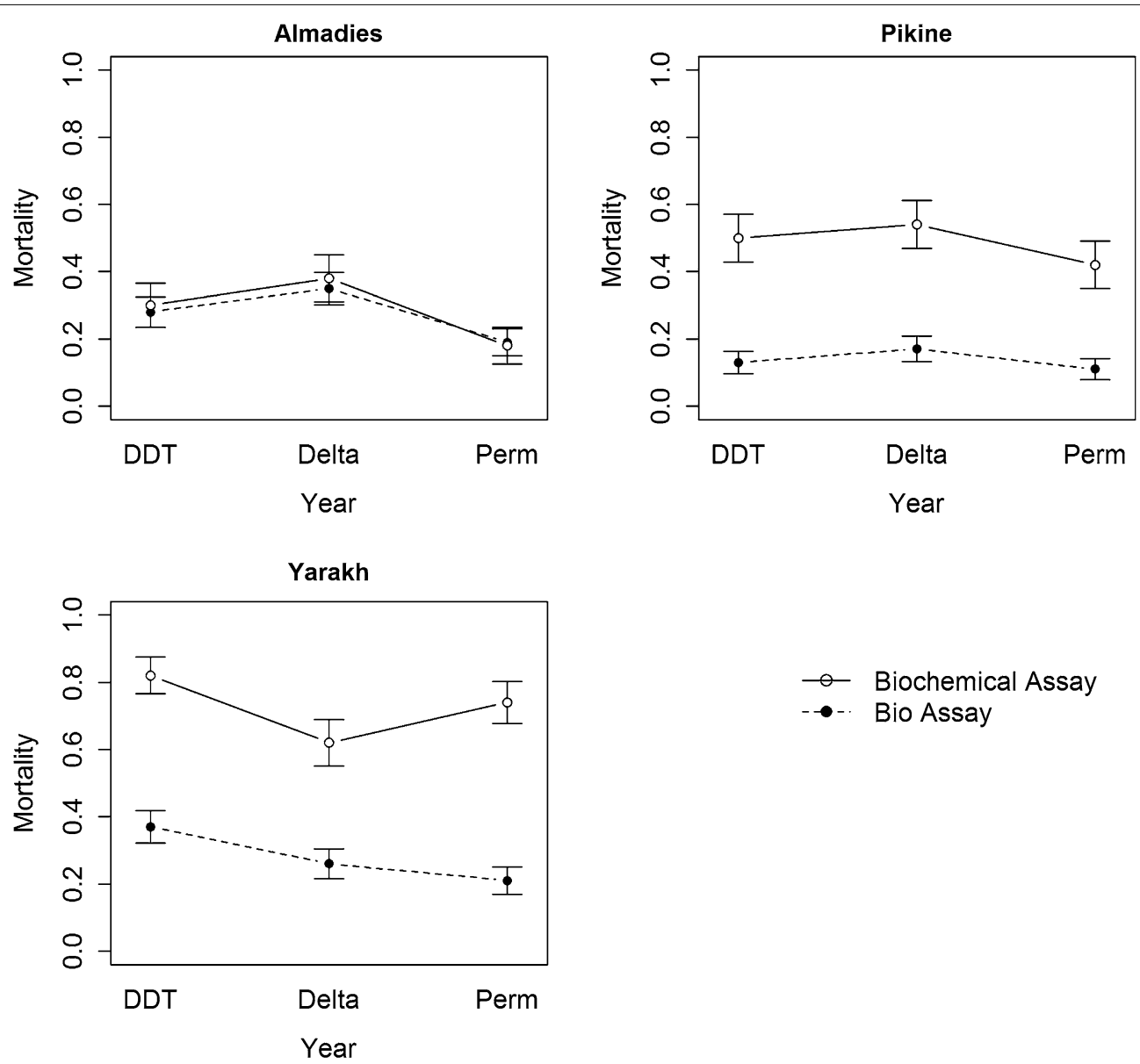

Fig. 3 Insecticide-induced mortality of mosquitoes in Almadies, Pikine and Yarakh measured by classical bioassay (dotted line) and biochemical assay (plain line). Error bars represent $95 \% \mathrm{Cl}$

The level of resistance to the different insecticides varied geographically, as indicated by the significant effect of the insecticide-site interaction on insecticide-induced mortality. The significance of the year variable, with no interaction with site or insecticide, indicates a trend to decreasing mortality (increasing resistance) over time. The genotype at the $k d r$ locus affects the mosquito's insecticide-induced mortality, indicating the involvement of the $k d r$ locus in the resistance of mosquitoes in Dakar. The trend to decreasing mortality within $k d r$ genotypes between 2010 and 2012, however, suggests that a further resistance mechanism might have evolved between those dates.

This study shows for the first time the presence of a high rate of $k d r-e$ mutations in Senegal and an increase in frequency over time. Previously, this mutation was observed only in East Africa [7], whereas it now appears to be invading West Africa [14], with the direct consequence of the disappearance of the barrier between $k d r-e$ and $k d r-w$, allowing significant gene flow among the different populations of anopheles and among bio-geographical regions.

The insecticide-induced mortality of SW genotypes was slightly higher than that of SE genotypes, which suggests that natural selection favours SE genotypes over SW genotypes and could explain the rapid increase in the frequency of $E$ alleles. This study demonstrated a significant effect of $k d r$ locus on mortality, SS genotypes being more sensitive than SE genotypes, SW genotypes being intermediary between SS and SE genotypes and EE genotypes being less sensitive than the other genotypes.

Djegbe et al. [14] described the presence of the $k d r$ $e$ allele in anopheles populations in West Africa for the first time in Benin, in 2011. Those authors found a low level of circulation of this allele, which was, however, sufficient as an indicator of diffusion. A part from $k d r$-type resistance, our study also showed physiological resistance 
of Anopheles to pyrethroids and DDT in all three neighbourhoods of Dakar studied, which increased over the years. In some areas, resistance to organophosphates and carbamates was exacerbated; however, even if the presence of the $k d r$ allele results, to a large extent, from the use of pesticides in the Niayes area [37], this cannot explain its high prevalence throughout the region, especially in coastal areas and in residential areas such as Almadies. Massive unplanned aerial spraying with insecticide should also be taken into consideration. As the frequency of $k d r-e$ was much higher in Dakar than in Benin, diffusion of $k d r-e$ to the interior of the continent in this part of West Africa could gather momentum. Additional studies are needed to test this hypothesis as well as the mechanisms of diffusion.

Strong resistance to insecticides is important for many reasons. Recent studies have shown that $k d r$-type resistance could seriously compromise the effectiveness of insecticide-treated nets [23,38], and the presence of $k d r$ mutations in Anopheles may significantly increase their susceptibility to Plasmodium infection [39]. The Senegalese national malaria control programme has embarked on a comprehensive initiative to provide nets for every bed, except in the Dakar region. Our results put into question this action. The presence of the $k d r-e$ allele, associated with high physiological and metabolic resistance to pyrethroids, could have a negative impact on vector control.

The finding that the mortality of mosquitoes in Pikine and Yarakh differed significantly with exposure to $\mathrm{PBO}$ before another insecticide indicates that these mosquitoes have an oxidase resistance mechanism. In contrast, the mortality rate of mosquitoes in Almadies was the same independently of their exposure to PBO, suggesting the absence of an oxidase resistance mechanism (cytochrome P450 monooxygenases). A significant oxidase resistance mechanism was seen in Yarakh and Pikine. These observations could explain why a given $k d r$ genotype results in different mortality depending on site, and selection of a mechanism could explain why mortality decreases for a given $k d r$ genotype over time (Fig. 3).

Resistance to fenitrothion and tolerance to bendiocarb have gradually begun to be seen in the Dakar region. Although a high frequency of ace1 was not found, further studies should be conducted to identify any other biochemical intermediate, such as esterases or glutathione-S-transferase. The various types of resistance observed in Anopheles populations $[5,40]$ could have disastrous consequences on the long road towards malaria eradication.

\section{Conclusion}

Widespread use of insecticides in indoor residual spraying and long-lasting insecticide-treated bed nets has a mixed role in the spread of the $k d r$ gene. If behavioural resistance is added, there is no doubt that the combination of these forms of resistance will slow or significantly alter vector control. There is room for hope, however, because, despite widespread resistance, the prevalence of malaria in Senegal has never been so low. The efforts that led to this result must be both sustained and maintained.

\section{Additional files}

Additional file 1. Evolution of kdr frequency in Anopheles arabiens populations collected in 44 sites in Dakar between 2007 to 2009.

Additional file 2. Insecticide-induced mortality of mosquitoes in Pikine, Yarakh and Almadies, with 95\% confidence intervals. "Sens." indicates sensitivity (mortality >98\%), "I.T." indicates increased tolerance (mortality 80-98\%), "Res." indicates resistance (mortality <80\%).

Additional file 3. Mortality predicted in the model for each genotype at each site, for each insecticide, each year. Several genotypes were not found at some sites; in particular, the SW genotype was found only in Yarakh.

Additional file 4. Insecticide-induced mortality of mosquitoes in Pikine, Yarakh and Almadies with and without prior exposure to PBO.

\section{Authors' contributions}

MON, FP and CR designed the study. MON and FP performed the field work. MON, FP and EOP performed the laboratory work. AC and PB analysed the data. MON and AC drafted the manuscript with contributions from PB and FP. MON, JFT, FP and CR supervised the study. All authors read and approved the final manuscript.

\section{Author details}

${ }^{1}$ Groupe G4 Institut Pasteur International Network, Institut Pasteur de Bangui, BP 237, Bangui, Central African Republic. ${ }^{2}$ Laboratoire de Paludologie et de Zoologie, Campus UCAD-IRD, BP 1386, CP 18524 Dakar, Senegal. ${ }^{3}$ Afrique One, Centre Suisse de Recherches Scientifiques, 01 BP 1303, Abidjan, Côte d'Ivoire. ${ }^{4}$ UMR 6236, Unité d'entomologie médicale, IRBA antenne Marseille, GSBDD Marseille Aubagne, 111 avenue de la Corse, BP 40026, 13568 Marseille Cedex 2, France. ${ }^{5}$ The Roslin Institute, The University of Edinburgh, Easter Bush, Edinburgh EH25 9RG, UK. ${ }^{6}$ Institut Pasteur de Madagascar, BP 1274 , Ambohitrakely, 101 Antananarivo, Madagascar.

\section{Acknowledgements}

We acknowledge all the Palu Urbain Team for their participation in field and laboratory work at different stages of the project. We thank finally Bill Brodgon from the CDC for insecticides training.

\section{Funding}

This work was supported by the French Research Institute for Development, the Direction Générale de l'Armement. The funders had no role in study design, data collocation or analysis, decision to publish or preparation of the manuscript. Ousmane Ndiath was supported by a G4-Group Pasteur Bangui (CAR) fellowship provided by the Institut Pasteur International Network. Aurélie Cailleau was supported by a fellowship from Afrique funded by the Wellcome Trust.

\section{Compliance with ethical guidelines}

\section{Competing interests}

The authors declare that they have no competing interests. This does not alter our adherence to all the Malaria Journal policies on sharing data and material.

Received: 17 February 2015 Accepted: 14 September 2015

Published online: 22 September 2015 


\section{References}

1. Ndiath MO, Mazenot C, Sokhna C, Trape JF. How the malaria vector Anopheles gambiae adapts to the use of insecticide-treated nets by African populations. PLoS One. 2014;9:e97700.

2. Trape JF, Tall A, Sokhna C, Ly AB, Diagne N, Ndiath O, et al. The rise and fall of malaria in a West African rural community, Dielmo, Senegal, from 1990 to 2012: a 22 year longitudinal study. Lancet Infect Dis. 2014;14:476-88.

3. WHO. World malaria report 2013. Geneva: World Health Organization; 2013.

4. Ranson H, N'Guessan R, Lines J, Moiroux N, Nkuni Z, Corbel V. Pyrethroid resistance in African anopheline mosquitoes: what are the implications for malaria control? Trends Parasitol. 2011;27:91-8.

5. Sokhna C, Ndiath $M O$, Rogier $C$. The changes in mosquito vector behaviour and the emerging resistance to insecticides will challenge the decline of malaria. Clin Microbiol Infect. 2013;19:902-7.

6. Martinez-Torres D, Chandre F, Williamson MS, Darriet F, Berge JB, Devonshire $\mathrm{AL}$, et al. Molecular characterization of pyrethroid knockdown resistance $(\mathrm{kdr})$ in the major malaria vector Anopheles gambiae s.s. Insect Mol Biol. 1998;7:179-84.

7. Ranson H, Jensen B, Vulule JM, Wang X, Hemingway J, Collins FH. Identification of a point mutation in the voltage-gated sodium channel gene of Kenyan Anopheles gambiae associated with resistance to DDT and pyrethroids. Insect Mol Biol. 2000;9:491-7.

8. Awolola TS, Oduola OA, Strode C, Koekemoer LL, Brooke B, Ranson H. Evidence of multiple pyrethroid resistance mechanisms in the malaria vector Anopheles gambiae sensu stricto from Nigeria. Trans R Soc Trop Med Hyg. 2009;103:1139-45.

9. Chandre F, Darriet F, Manguin S, Brengues C, Carnevale P, Guillet P. Pyrethroid cross resistance spectrum among populations of Anopheles gambiae s.s. from Cote d'Ivoire. J Am Mosq Control Assoc. 1999;15:53-9.

10. Fanello C, Petrarca V, della Torre A, Santolamazza F, Dolo G, Coulibaly M, et al. The pyrethroid knock-down resistance gene in the Anopheles gambiae complex in Mali and further indication of incipient speciation within An. gambiae s.s. Insect Mol Biol. 2003;12:241-5.

11. Czeher C, Labbo R, Arzika I, Duchemin JB. Evidence of increasing Leu-Phe knockdown resistance mutation in Anopheles gambiae from Niger following a nationwide long-lasting insecticide-treated nets implementation. Malar J. 2008;7:189.

12. Diabate A, Baldet T, Chandre F, Akoobeto M, Guiguemde TR, Darriet F, et al. The role of agricultural use of insecticides in resistance to pyrethroids in Anopheles gambiae s.l. in Burkina Faso. Am J Trop Med Hyg. 2002;67:617-22.

13. Awolola TS, Oduola AO, Oyewole IO, Obansa JB, Amajoh CN, Koekemoer $\mathrm{LL}$, et al. Dynamics of knockdown pyrethroid insecticide resistance alleles in a field population of Anopheles gambiae s.s. in southwestern Nigeria. J Vector Borne Dis. 2007:44:181-8.

14. Djegbe I, Boussari O, Sidick A, Martin T, Ranson H, Chandre F, et al. Dynamics of insecticide resistance in malaria vectors in Benin: first evidence of the presence of L1014S kdr mutation in Anopheles gambiae from West Africa. Malar J. 2011;10:261.

15. Etang J, Fondjo E, Chandre F, Morlais I, Brengues C, Nwane P, et al. First report of knockdown mutations in the malaria vector Anopheles gambiae from Cameroon. Am J Trop Med Hyg. 2006;74:795-7.

16. Moreno M, Vicente JL, Cano J, Berzosa PJ, de Lucio A, Nzambo S, et al. Knockdown resistance mutations ( $k d r)$ and insecticide susceptibility to DDT and pyrethroids in Anopheles gambiae from Equatorial Guinea. Trop Med Int Health. 2008;13:430-3.

17. Pinto J, Lynd A, Elissa N, Donnelly MJ, Costa C, Gentile G, et al. Co-occurrence of East and West African kdr mutations suggests high levels of resistance to pyrethroid insecticides in Anopheles gambiae from Libreville, Gabon. Med Vet Entomol. 2006;20:27-32.

18. Verhaeghen K, Van Bortel W, Roelants P, Backeljau T, Coosemans M. Detection of the East and West African kdr mutation in Anopheles gambiae and Anopheles arabiensis from Uganda using a new assay based on FRET/melt curve analysis. Malar J. 2006;5:16.

19. Stump AD, Atieli FK, Vulule JM, Besansky NJ. Dynamics of the pyrethroid knockdown resistance allele in western Kenyan populations of Anopheles gambiae in response to insecticide-treated bed net trials. Am J Trop Med Hyg. 2004;70:591-6.

20. Pinto J, Lynd A, Vicente JL, Santolamazza F, Randle NP, Gentile G, et al. Multiple origins of knockdown resistance mutations in the Afrotropical mosquito vector Anopheles gambiae. PLoS One. 2007;2:e1243.

21. Pages F, Texier G, Pradines B, Gadiaga L, Machault V, Jarjaval F, et al. Malaria transmission in Dakar: a two-year survey. Malar J. 2008;7:178.

22. Trape JF, Sauvage C, Ndiaye O, Douillot L, Marra A, Diallo A, et al. New malaria-control policies and child mortality in senegal: reaching millennium development goal 4. J Infect Dis. 2012;205:672-9.

23. Trape JF, Tall A, Diagne N, Ndiath O, Ly AB, Faye J, et al. Malaria morbidity and pyrethroid resistance after the introduction of insecticide-treated bednets and artemisinin-based combination therapies: a longitudinal study. Lancet Infect Dis. 2011;11:925-32.

24. Ndiath MO, Sougoufara S, Gaye A, Mazenot C, Konate L, Faye O, et al. Resistance to DDT and pyrethroids and increased kdr mutation frequency in An. gambiae after the implementation of permethrin-treated nets in Senegal. PLoS One. 2012;7:e31943.

25. Hay SI, Guerra CA, Tatem AJ, Atkinson PM, Snow RW. Urbanization, malaria transmission and disease burden in Africa. Nat Rev Microbiol. 2005;3:81-90.

26. Bogreau H, Renaud F, Bouchiba H, Durand P, Assi SB, Henry MC, et al. Genetic diversity and structure of African Plasmodium falciparum populations in urban and rural areas. Am J Trop Med Hyg. 2006;74:953-9.

27. Keiser J, Utzinger J, Caldas de Castro M, Smith TA, Tanner M, Singer BH. Urbanization in sub-Saharan Africa and implication for malaria control. Am J Trop Med Hyg. 2004;71:118-27.

28. Donnelly MJ, McCall PJ, Lengeler C, Bates I, D'Alessandro U, Barnish G, et al. Malaria and urbanization in sub-Saharan Africa. Malar J. 2005;4:12.

29. Kristan M, Fleischmann H, della Torre A, Stich A, Curtis CF. Pyrethroid resistance/susceptibility and differential urban/rural distribution of Anopheles arabiensis and An. gambiae s.s. malaria vectors in Nigeria and Ghana. Med Vet Entomol. 2003;17:326-32.

30. Machault V, Gadiaga L, Vignolles C, Jarjaval F, Bouzid S, Sokhna C, et al. Highly focused anopheline breeding sites and malaria transmission in Dakar. Malar J. 2009;8:138.

31. Gadiaga L, Machault V, Pages F, Gaye A, Jarjaval F, Godefroy L, et al. Conditions of malaria transmission in Dakar from 2007 to 2010. Malar J. 2011;10:312.

32. WHO. Test procedures for insecticide resistance monitoring in malaria vectors, bio-efficacy and persistence of insecticides on treated surfaces. Geneva: World Health Organization; 1998.

33. Weill M, Malcolm C, Chandre F, Mogensen K, Berthomieu A, Marquine M, et al. The unique mutation in ace-1 giving high insecticide resistance is easily detectable in mosquito vectors. Insect Mol Biol. 2004;13:1-7.

34. Bass C, Nikou D, Donnelly MJ, Williamson MS, Ranson H, Ball A, et al. Detection of knockdown resistance $(\mathrm{kdr})$ mutations in Anopheles gambiae: a comparison of two new high-throughput assays with existing methods. Malar J. 2007;6:111.

35. Fanello C, Santolamazza F, della Torre A. Simultaneous identification of species and molecular forms of the Anopheles gambiae complex by PCRRFLP. Med Vet Entomol. 2002;16:461-4

36. Gary K, Zeng L. Logistic regression in rare events data. Polit Anal. 2001;9:137-63.

37. Faye O, Gaye O, Diallo S. Evaluation of the sensitivity of Anopheles gambiae to fenitrothion, malathion and DDT in Senegal. Dakar Med. 1991;36:170-7.

38. Corbel V, Akog beto M, Damien GB, Djenontin A, Chandre F, Rogier C, et al. Combination of malaria vector control interventions in pyrethroid resistance area in Benin: a cluster randomised controlled trial. Lancet Infect Dis. 2012;12:617-26.

39. Ndiath MO, Cailleau A, Diedhiou SM, Gaye A, Boudin C, Richard V, et al. Effects of the kdr resistance mutation on the susceptibility of wild Anopheles gambiae populations to Plasmodium falciparum: a hindrance for vector control. Malar J. 2014;13:340

40. Edi CV, Djogbenou L, Jenkins AM, Regna K, Muskavitch MA, Poupardin $R$, et al. CYP6 P450 enzymes and ACE-1 duplication produce extreme and multiple insecticide resistance in the malaria mosquito Anopheles gambiae. PLoS Genet. 2014;10:e1004236. 